\title{
Educational Multi-Sensory Game for Students with Mental Retardation
}

\author{
Alexopoulou Alexandra, Kastampolidou Kalliopi, and Bobori Catherine
}

\begin{abstract}
In this paper a game has been developed using the Scratch platform and its aim is to lighten the learning difficulties resulting from Mental Retardation (intellectual disability) and enhance the students' understanding. Through the use of a multi - sensory method, an alternative way of teaching is proposed suitable for students who need a differentiated education. Basic meanings are explained in a theoretical level, as well as the steps followed for the design of the game.
\end{abstract}

Index Terms-Mental Retardation; Educational Game; Scratch.

\section{INTRODUCTION}

The aim of this paper is the development of a thematic game for the primary school's History with particular emphasis in the interaction and narration of it. This game is suitable for students with learning difficulties resulting from Mental Retardation. Thus, its aim is to keep their interest during this experience so that their difficulties can be eased. An alternative method of learning is presented through the multi - sensory method.

Mental Retardation is not only one of the most well studied disorder but also one of the most common [1]. As a group, it has a lot of variations in the cause, the index intelligence, the social adaptation and the problems that coexist. It is a disorder that affects important aspects of a person's everyday life [1].

The game is created in a Scratch platform, which is a useful tool for any software development due to its simple and understandable creating application system.

\section{Mental Retardation}

\section{A. Definitions}

"Mental Retardation is a disorder which is characterized from essential restrictions not only in mental function but also in adaptive behavior, according to the various conceptual social and practical adaptive abilities" [2]. This disorder appears before the age of 18 years old [2] with concurrent malfunctions or disabilities in the adaptive ability in, at least, two of the following areas: communication, self - handling, home life, social - interpersonal skills, usage of the community funds, self-guidance, functional academic skills, work, amusement, health and security [3].

Published on February 2018.

A. Alexopoulou is with the Hellenic Open University, Athens, Greece (e-mail: alexopoulou_al@hotmail.com).

K. Kastampolodou is with the Department of Informatics, Ionian University, Corfu, Greece. (e-mail: c16kast@ionio.gr).

C. Bobori is with the Department of Informatics, Ionian University, Corfu, Greece (e-mail: k.bobori@ionio.gr).

\section{B. Classification of Mental Retardation}

Most classification systems describe Mental Retardation based on the severity of the disability, the cause and also the symptoms of the syndrome. However the most widespread criteria for this classification seems to be the intelligence index and the most accepted dissociation is the one of the American Association on mental deficiency. Based on this, Mental Retardation is categorized in the following 5 stages: borderline ( 70 up to 80 ), mild ( $50-55$ ), medium ( 35 40 ), serious ( $20-25$ up to $35-40$ ) and severe ( under 20 $-25)$.

Nevertheless we must emphasize the fact that the intelligence index is only one individual characteristic and we must be extremely careful when we define it [1]. Even though, it is a decisive categorization tool for this mixed population, its use has been criticized severely and it still divides the scientific community [4].

This game is mostly recommended for children with mild or medium mental retardation so that the exercises, the games and the vocabulary which are used in it, could be positive and supportive for the whole attempt. Nowadays the co - education of children with and without special educational needs makes us realize and respect diversity [5]. One of the goals for co - education is the abolishment of special education and the promotion of education for all the children with special educational needs in general schools [6]. We must ensure not only to obtain knowledge and abilities but also their social incorporation. Thus, we recommend this game to boost children's relations since students with typical or higher intelligence index could be their teachers "playing" with students with lower intelligence index.

\section{MethodologY}

\section{A. Game objective}

In this paper we used Scratch in order to develop an educational game which the teacher will use in order to present a part of the Third Grade's History syllabus. We emphasize in the interaction and the narration of the history since this game aims to enhance the traditional teaching methods. Particularly, this game has been developed in order to ease the learning difficulties that people with Mental Retardation face through the use of a multi - sensory method.

Awakening consciousness to children with Mental Retardation promotes the learning process while helping them to gain experience so that they can interact and communicate more successfully with their environment. Multi-sensory approach is a method that encompasses many and alternative ways of communication (images, symbols, 
reference objects, assistive technology) that enhance the perception, understanding and communication of children with severe learning difficulties, such as children with Mental Retardation [7]. In particular, images play a decisive and ancillary role in learning by offering a number of assets that make this educational game the most suitable for students with diagnosed Mental Retardation.

\section{B. Syllabus summary - Lesson plan}

This game is suggested to teachers to use it, after having previously presented and taught extensively the relevant chapter of the story. Also, the detailed explanation of how this game works in order to have immediate results, as well as the first contact of the child with it, is also very important.

Specifically, it is proposed to divide each section of the syllabus into chapters according to the game. Then, the teacher will explain the lesson and read it along with their students in the traditional way of teaching. Once this initial presentation has been completed, each student will, according to their teacher's suggestion, select the corresponding level, listen to the narrative, and observe the images. Before doing so, the teacher should point out to the students to concentrate, as much as possible, not only on the pictures but also on the sound presentation of the story. It is then considered that students will be able to "play" with the relevant activities presented in each level, which have been selected on the basis of scaling difficulty, in order to always maintain high self-efficiency and motivation for the students.

Concluding, as it has already been suggested, students with a standard or higher intelligence index could create groups with lower cognitive students to collaborate and successfully solve each activity. At the same time, the role of the teacher could be taken over by students with a low intelligence index as soon as they become familiar with the application, in order to enhance both their self-esteem and self-confidence, as well as the appreciation and image they present to their classmates.

\section{Game specifications}

The game designed in this work was implemented according to the principles of block programming. The Scratch platform itself works with block programming logic, where blocks of already-made commands are used. This game is a multimedia application, combining elements such as images and animations, sound (music and narration) and text to represent, present and transmit knowledge [8].

The game was designed in a simple manner aiming to the target audience and the fact that it will be used for educational purposes. The material used was drawn from the schoolbook of the Third Grade of Primary School, due to the already existing familiarity of students with the pictures of the school manual. Its main features are the images, which work supportively in the narration, and the text, which is projected in "dialog bubbles". The use of animated images as a mean of reward to the pupils aims at the recognition of their effort and a motivation for them to participate in the learning process [9]. In addition, small tasks - activities are used so that the student can achieve a small repetition of the syllabus. These games are in a staggering difficulty as they start with multiple choice questions to questions whose answer is the selection of the correct image and are completed by crossword puzzles.

The nature of the game is such that even if the teachers do not have the necessary familiarity with a computer, they can handle it and use it as part of the educational process. Respectively, students can use it at home for further training as it is also available online through the Scratch platform, which is now widely used by the educational community.

The game can be reached in the following link https://scratch.mit.edu/projects/169607955/ .

\section{Game platform}

Scratch is a specially designed program from the Lifelong Kindergarten Group of the MIT Media Lab, which is provided for free through its official website (https://scratch.mit.edu/). It mainly refers to people from 8 to 16 years of age, without excluding its use by people of other ages. Users create Scratch projects from their personal computer. The platform is currently used in schools, museums, libraries and cultural centers to educate students and learners around a subject with the broad exploitation of new technologies.

With Scratch anyone can program and share his own stories, game or even animated series in the online community or use them as a teaching technique. Scratch is currently used as a way of learning to think creatively, to issue situations and to cooperate actively with other people.

Simultaneously, teachers can use Scratch in the school environment, as the level of education required varies from Primary School to University, depending on the work and the purpose for which each application/game is created. The thematic areas that this program can cover have no limits, ranging from languages, sciences and social studies to mathematics, computer science and the arts.

\section{GAME PRESENTATION}

The default screen and a menu with an introductory song are shown as long as the game begins. The menu includes five (5) levels and an extra one (' includes extra games for further practice (Fig. 1).

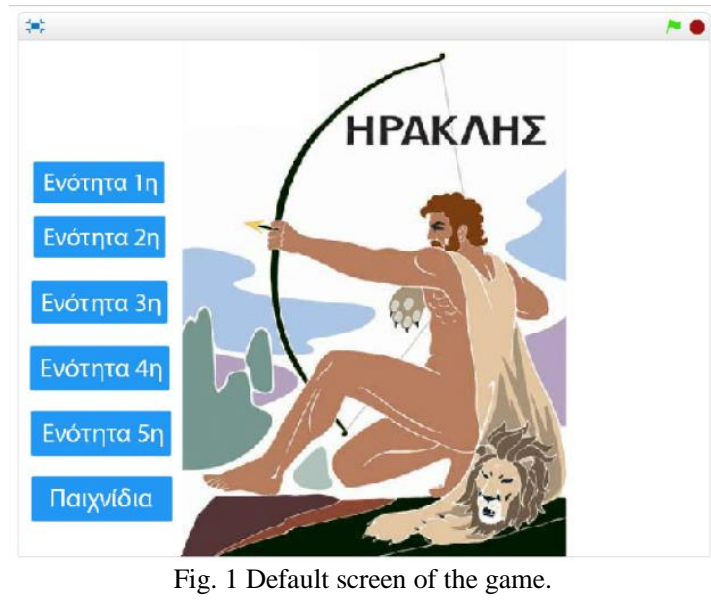

By choosing a level, the narration of the story starts accompanied with a series of explanatory images that are used as a revision method of the syllabus. The images and narration describe in brief, using small sentences, Hercules' 
life as well as some of the tasks he was given. In the end of each level there is an activity for the students in order to evaluate their level of understanding. The activities are either multiple choice questions, crosswords or questions that use images as a reply. The chosen narrator is "Megara" as she is designed in the Disney movie in an attempt to make the game more interesting for the students as well as likeable.

Specifically, for the first level, the student will learn about the "Birth of Hercules" through the images and narration. After the narration is over, an activity is given to the students. In case the answer is correct, a congratulatory message in the form of a gif is presented. If the answer is wrong, a new character is introduced, "Phil or Philoctetes" who appears and gives an error message (Fig. 2).

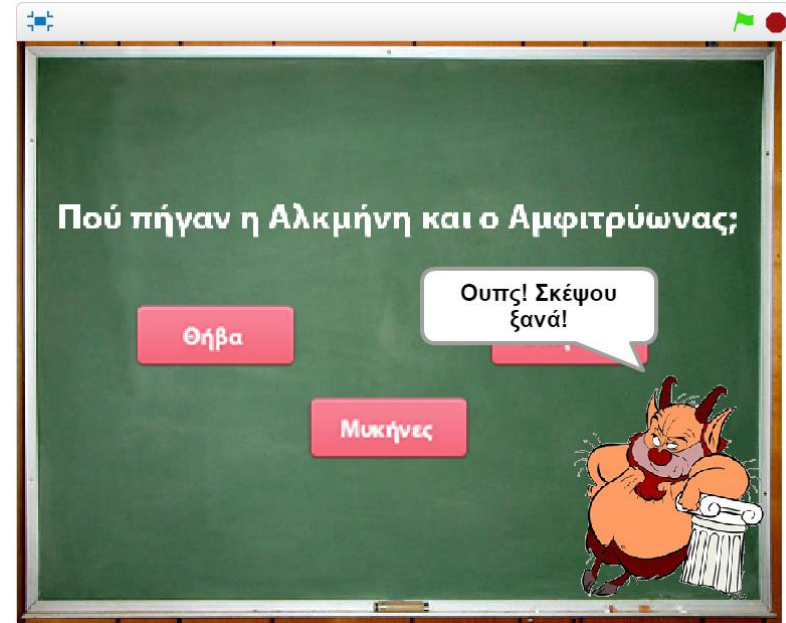

Fig. 2 Philoctetes gives the error message to the students as an indication of their wrong answer.

In the second level, the students learn about Hercules' adult life until his visit to the Oracle of Delphi. In this level there is a task that revises the narrated syllabus too. The student progresses to the next level after the congratulatory message is shown.

In the third level, the learning of the tasks of Hercules starts. The narrations is continuous while we can see an extra character, Hercules, who interacts with the students urging them to learn about the next task which in turn gives a feeling of interaction in the game (Fig. 3).

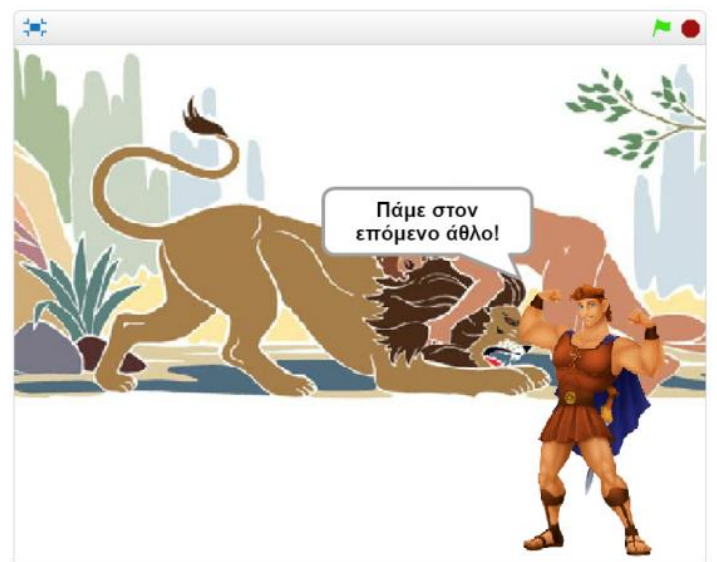

Fig. 3 Hercules urges the students to learn more about his tasks.
The given activities are questions with the use of images as replies and the students are asked to choose which of the three is the correct one (Fig. 4). The error control is performed exactly as in the case of the simple multiple choice questions.

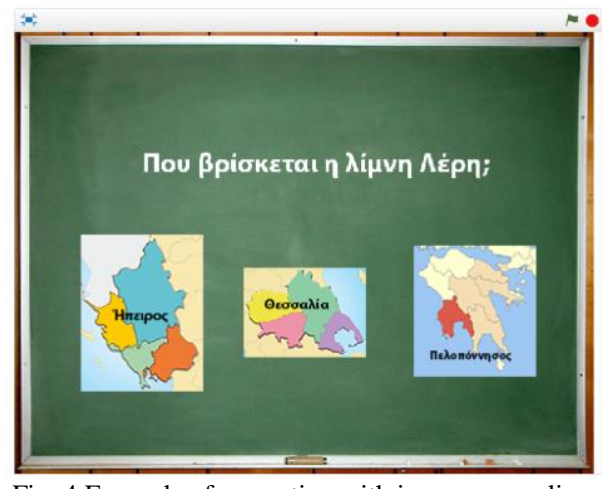

Fig. 4 Example of a question with images as replies.

Continuing to the forth level we can see similar multimedia which help us learn about Hercules' tasks. In this level, we use a multiple choice question as well as an image related question as revision tasks. However, in the fifth level the end of Hercules' life is presented. The given task is a crossword which contains knowledge from all the previous levels.

Finally, the extra level ('M $\alpha \imath v$ ví $\delta \alpha$ ') includes two game categories. The first one is a crossword and the second is a series of four multiple choice questions. The aim of this extra level is to provide the students with extra tasks for further practice and fun (Fig. 5).

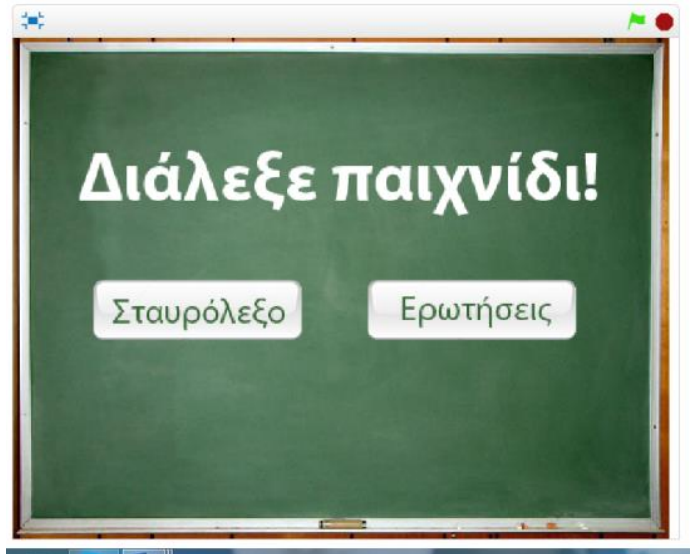

Fig. 5 Menu for the extra level of the game.

\section{CONCLUSION}

In summary, with this work we attempted to create a game through which it would be possible to teach the lesson of History of the Third Grade to Primary Schoolers. This application is proposed to be used after the delivery of the relevant chapter of history, which will be divided into parts corresponding to those of the game, so that the students' understanding is reinforced through the audio and visual narrative that is offered. This game is a suggestion for teaching with the use of new technologies, which should be tested and evaluated in real life conditions and in a classroom, before it will be considered suitable for students with a diagnosed Mental Retardation. However it could be used by students of regular or superior intellectual potential 
as well, thus enhancing both the interest of children and the inclusion of students with and without special educational needs.

At the same time, this game can take advantage of a variety of activities, such as creating puzzles with images that are on the screen on a fainter background and on which the right pieces (4-5 pieces) will be placed, keeping the students' interest high. Finally, we ought to note that this game is in a preparatory stage which explains the lack of clinical data. This further planning will be part of our future work along with game play improvements.

\section{ACKNOWLEDGMENT}

The dialogs and narration about Hercules' life and tasks as it is heard during the game is adapted from the Second Unit of the History book for the Third Grade, published by the Greek Ministry of Education, Research and Religious Affairs. The images that were used for the development of the game are adapted from Disney's movie, "Hercules" (1997). Finally, the introductory song of the game is "The Prince" produced by Heo Sang-Eun. The song's first release was for the S. Korean TV series «Moon Lovers: Scarlet Heart Ryeo» (달의 연인 - 보보경심 려) (2016).

\section{REFERENCES}

[1] S. Charitou, Noitiki Kathisterisi, Anavathmisi kai epektasi toy thesmou tis ekpaideysis atomon me sovara provlimata igeias pou vriskontai gia megalo xroniko diastima se nosileytika idrimata $i$ sto spiti, In E.P.E.A.E.K (Е.П.Е.A.E.K.), 2005, pp. 14-37 [online] Available: http://repository.edulll.gr/697. (in Greek)

[2] W. L. Heward, Paidia me eidikes anagkes. Mia eisagogi stin Eidikh Ekpaideysi. Editors: A. Davazoglou \& K. Kokkinos, Athens, Topos, 2011.

[3] American Psychiatry Association. Diagnostic and Statistical Manual of Mental Disorders (fourth edition). USA: Washington, DC., 2013.

[4] V. Strogillos, Apotelesmatikes praktikes stin ekpaideysh ton paidion me noitiki sterisi. Editors: S. Panteliadou \& V. Argyropoulos, Eidiki agogi apo tin ereyna stin praksi. pp 253-299. Athens: Pedio, 2011.

[5] V. Lamproboulou, and S. Panteliadou, H eidiki Agogi stin ElladaKritiki theorisi. Pan-Hellenic Federation of Parents' Associations of Children with Dyslexia and Learning Difficulties, 2010, [Online] Available: http://www.dyslexiagoneis.gr/view.asp?ItemID=109\&ns=1\&mcid=9\&cid=23\&scid=16 (in Greek)

[6] W. Stainback, and S. Stainback, Support networks for inclusive schooling: Interdependent integrated education. Baltimore: Paul $\mathrm{H}$ Brookes, 1990.

[7] J. Porter, and R. Ashdown, Pupils with Complex Learning Difficulties: Promoting learning using visual materials and methods. Tamworth: NASEN, 2002.

[8] K. Barbatsis, D. Oikonomou, I. Papamagana and I. Zozas. Hlektronika Paixnidia os Ekpaideytika Ergaleia. 2nd Panhellenic Conference on Education in Imathia. Psifiakes kai diadiktiakes Efarmoges stin Ekpaideysi, 2010. (in Greek)

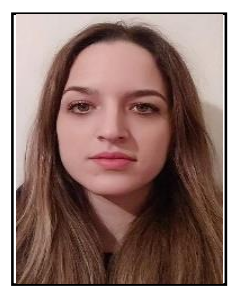

Alexandra Alexopoulou was born in Athens in 1993 and is a Postgraduate Student in the Department of Special Education in Hellenic Open University since 2016. She completed her undergraduate studies at University of Patras in the Department of Greek Literature in 02/2016. Her research interests lie in the area of education, special education, differentiated teaching, teaching methods and educational technology.

She has volunteer experience as Tutor in children with special learning disabilities at annex of child protection in Achaia (Skagiopoulio, 2013) and currently works as Tutor in a private institution in Glyfada.

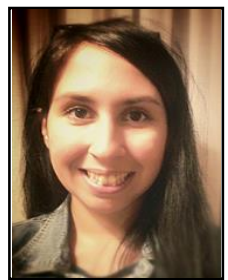

Kalliopi Kastampolidou was born in Thessaloniki in 1994 and is a Postgraduate Student in the Departmen of Informatics at the Ionian University in Corfu since 2016. She completed her undergraduate studies at Ionian University in the aforementioned Department in 09/2016 under the supervision of Theodore Andronikos. Her research interests lie in the area of quantum and unconventional computation, quantum game theory, automata theory, programming languages, semantic web and robotics.

She has volunteer experience as Library Assistant at Ionian University's Library (2013) and as a team's coach in FLL robotics competition (2018). Also, she assists in various lab and tutorial lessons for various courses in the Department of Informatics since 2016. She holds a position of IT support and library duties in the Department of Music studies at Ionian University.

Kalliopi Kastampolidou is a member of QUIT since 2015. She was awarded a scholarship from the department for postgraduate studies in the MSc Informatics.

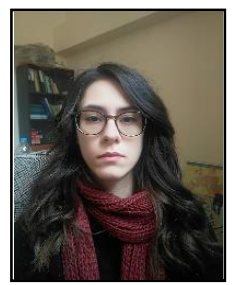

Katherine Bobori was born in Ionnina in 1994. She is a Post Graduate Student in Department of Informatics at the Ionian University. Catherine Bobori graduated from the same Department with a Diploma in Informatics (2012). She then continued her studies in the Master's Program "Bioinformatics and Neuroinformatics" (2016).

She has worked as a secretary at the Ionian University for the last two years as well as helped with the organization of the last two GeNeDis Congresses. She has a number of publications in Conferences such as GeNeDis, IISA, ISSPIT and CIE. Her research interest mainly lies in the area of bioinformatics and systems biology with applications in neurodegerative diseases and virology.

Mrs Bobori is a member of the Bioinformatics and Human Electrophysiology Laboratory as well as QUIT. 